Supporting Information

\title{
A Versatile Strategy for Quantum Dots Ligand Exchange
}

\author{
Fabien Dubois, Benoît Mahler, Benoît Dubertret, Eric Doris*, and Charles Mioskowski*
}

\section{General methods}

Reagents were purchased from Aldrich except carbon disulfide that was purchased from Fluka. NMR Spectra were recorded on a Bruker AVANCE DPX 400 spectrometer. Chemical shifts are given in ppm relative to $\mathrm{CHCl}_{3}$ (7.26 ppm) for ${ }^{1} \mathrm{H} \mathrm{NMR}$ and relative to $\mathrm{PPh}_{3}(0 \mathrm{ppm})$ for ${ }^{31} \mathrm{P} \mathrm{NMR}$. UV spectra were obtained using a Varian CARY 50 Probe UV-Vis spectrometer. Fluorescence spectra were measured on a Jobin-Yvon Fluoromax-3. Photostability experiments were performed with a Gemini XPS microplate spectrofluorometer from Molecular Devices. Transmission electron microscopy pictures were obtained with a Phillips CM 12 microscope $(120 \mathrm{kV})$ using carbon-coated grids.

\section{Nanocrystal synthesis}

Synthesis of CdSe/ZnS nanocrystals: $\mathrm{CdSe} / \mathrm{ZnS}$ nanocrystals were synthesized using modifications of the syntheses first developed by Murray [1] and Hines [2]. Typically, 20mL of a $0.25 \mathrm{M}$ TOPSe solution containing $150 \mu \mathrm{L}$ of dimethylcadmium was swiftly injected in $30 \mathrm{~g}$ of degassed TOPO solution heated at $350^{\circ} \mathrm{C}$. When the CdSe nanoparticles reached the desired size, the nanoparticles were isolated with methanol/butanol precipitation and suspended in hexane. $\mathrm{ZnS}$ layers were grown as described in [3]. After synthesis, the QDs were precipitated with methanol/butanol and suspended in hexane.

Synthesis of $\mathrm{CdSe} / \mathrm{CdS} / \mathrm{CdZnS} / \mathrm{ZnS}$ nanocrystals: Core/multi-shell nanocrystals were prepared using a modified literature method $[1,4,5]$. Briefly, CdSe nanocrystals were synthesized by a rapid injection of a solution composed of $4 \mathrm{~mL}$ tributylphosphine selenide (TBPSe) $1 \mathrm{M}, 3 \mathrm{~mL}$ oleylamine and $1 \mathrm{~mL}$ octadecene into a degassed solution of $750 \mu \mathrm{L} \mathrm{Cd}(\text { oleat })_{2} 0.5 \mathrm{M}$ in oleic acid and $8 \mathrm{~mL}$ octadecene at $280^{\circ} \mathrm{C}$. The growing CdSe nanocrystals were then maintained at $250^{\circ} \mathrm{C}$ until the desired size was reached (typically $3 \mathrm{~nm}$ diameter). After precipitation, the dots were suspended in $10 \mathrm{~mL}$ of hexane. The shells were grown using a SILAR procedure $[4,6]$. Typically, a hexane solution of CdSe nanocrystals, $3 \mathrm{~mL}$ octadecene and $2 \mathrm{~mL}$ oleylamine were degassed at $70^{\circ} \mathrm{C}$ during one hour. The solution is then heated to $230^{\circ} \mathrm{C}$ under an atmosphere of Ar. The different shell layers $(\mathrm{CdS}, \mathrm{CdZnS}$ and $\mathrm{ZnS})$ were grown by successive injections of Cd(oleat $)_{2}$ or $\mathrm{Zn}(\text { oleat })_{2} 0.1 \mathrm{M}$ in octadecene and sulphur $0.1 \mathrm{M}$ in octadecene. Reaction times were adjusted to allow complete reaction of the precursors injected. Exact amounts of precursors were calculated to coat CdSe nanocrystals with 2 monolayers of $\mathrm{CdS}, 3$ monolayers of $\mathrm{Cd}_{0.5} \mathrm{Zn}_{0.5} \mathrm{~S}$ and 4 monolayers of $\mathrm{ZnS}$. After synthesis, the QD were precipitated with acetone after two methanol extractions.

1. Murray, C. B.; Norris, D. J.; Bawendi, M. G. J. Am. Chem. Soc., 1993, 115, 8706-8715.

2. Hines, M. A.; Guyot-Sionnest, P. J. Phys. Chem. 1996, 100, 468-471.

3. Dabbousi, B. O.; Rodriguez-Viejo, J.; Mikulec, F. V.; Heine, J. R.; Mattoussi, H.; Ober, R.; Jensen, K. F.; Bawendi, M. G. J. Phys. Chem. B. 1997, 101, 9463-9475.

4. Xie, R.; Kolb, U.; Li, J.; Basché, T.; Mews. J. Am. Chem. Soc. 2005, 127, 7480-7488.

5. $\quad$ Peng, Z. A.; Peng, X. J. Am. Chem. Soc. 2001, 123,183-184.

6. Li, J. J.; Wang, Y. A.; Guo, W.; Keay, J. C.; Mishima, T. D.; Johnson, M. B.; Peng, X. J. Am. Chem. Soc. 2003, 125, 12567-12575. 
A typical procedure for the exchange of ligands using aliphatic or aromatic amines is given for the preparation of $Q D-2 e$.

$300 \mu \mathrm{L}$ of a $10^{-3} \mathrm{M}$ solution of QDs (300 nmol) in hexane were precipitated in $\mathrm{MeOH}(5 \mathrm{~mL})$. The supernatant is discarded and the QDs are redissolved in $\mathrm{CHCl}_{3}(1 \mathrm{~mL})$. Di-n-octylamine in large excess $(100 \mathrm{mg}, 0.4 \mathrm{mmol}$ ) was added, followed by an equimolar quantity of carbon disulfide (30 $\mathrm{mg}, 0.4 \mathrm{mmol}$ ). The solution was stirred for 3 hours at room temperature. The nanocrystals were then precipitated two times in $\mathrm{MeOH}(2 \times 5 \mathrm{~mL})$. The supernatant was discarded and the newly coated dithiocatbamate-QDs were collected and dissolved in various organic solvents such as $\mathrm{CHCl}_{3}$, THF, etc.

Fluorescence spectra were recorded (excitation at $350 \mathrm{~nm}$ ) and indicated that emissions of the coreshell-QD before and after ligands exchange are nearly identical with peak shifts lower than $3 \mathrm{~nm}$.

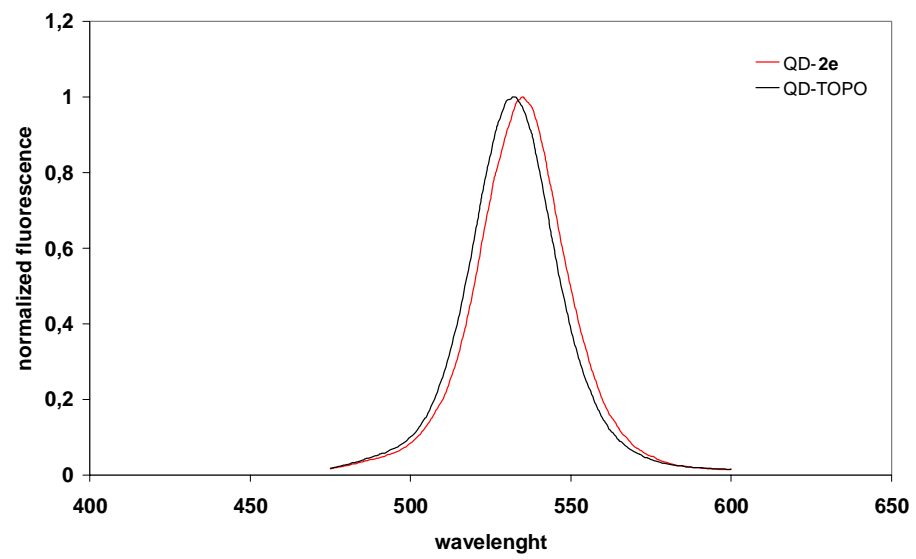

Figure 1: Normalized fluorescence spectra before and after ligand exchange (excitation at $350 \mathrm{~nm}$ ).

Impact of ligand exchange on the fluorescence properties of core-QDs and core-shell-QDs.

The fluorescence of core-QDs and core-shell-QDs were recorded in $\mathrm{CHCl}_{3}$ every second after addition of both reagents i.e., di-n-octylamine and 1 equiv of $\mathrm{CS}_{2}$. While the fluorescence intensity of core-shell-QDs remained nearly constant over extended period of time, fast extinction of the photoluminescence of core only-CdSe nanoparticles was observed in the presence of $\mathrm{CS}_{2}$ and di-noctylamine.

The presence of the shell is therefore essential to maintain optical properties of the QDs as the photostability of QD-2e is identical to that observed for original QD-TOPO in chloroform. 


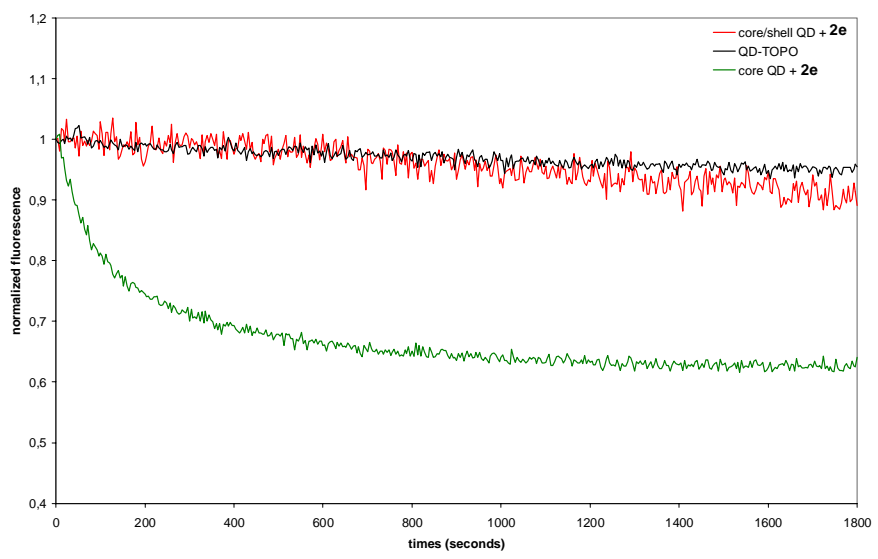

Figure 2 : Fluorescence stability in function of time after the addition of $\mathrm{CS}_{2}+\mathrm{R}_{1} \mathrm{R}_{2} \mathrm{NH}$.

A typical procedure for the exchange of ligands using amino-acids is given for the preparation of $Q D-2 a$.

$100 \mu \mathrm{L}$ of a $10^{-3} \mathrm{M}$ solution of QDs $(100 \mathrm{nmol})$ in hexane were precipitated in $\mathrm{MeOH}$. The supernatant is discarded and the QDs are redissolved in $\mathrm{MeOH} / \mathrm{CHCl}_{3}$ 1:1 (3 mL). In a separate flask, a solution of glycine $(80 \mathrm{mg}, 1.06 \mathrm{mmol})$ in the same mixture of solvents $(2 \mathrm{~mL})$ was reacted with tetramethylammonium hydroxide pentahydrate $\left(384 \mathrm{mg}, 2\right.$ equiv) and $\mathrm{CS}_{2}(81 \mathrm{mg}, 1.06$ $\mathrm{mmol})$. To the latter is added the solution of QDs and the mixture is stirred at room temperature for 12 hours. Diethylether $(5 \mathrm{~mL})$ is then added and the precipitate is isolated by centrifugation. The supernatant is discarded and the QDs were dissolved in methanol, precipitated with $5 \mathrm{~mL}$ of THF and centrifuged again. The resulting solid is finally dissolved in $\mathrm{pH} 8.5$ Tris buffer $[0.1 \mathrm{M}]$.

\section{Stability experiments}

Photostability of an aqueous solution of QDs-2a was measured at $570 \mathrm{~nm}$ by consecutive excitation (one every 4 seconds) at $350 \mathrm{~nm}$. The fluorescence intensity is normalized to the initial value. After 500 successive illuminations, $85 \%$ of the initial fluorescence intensity remained and no difference in the emission shifts were observed.
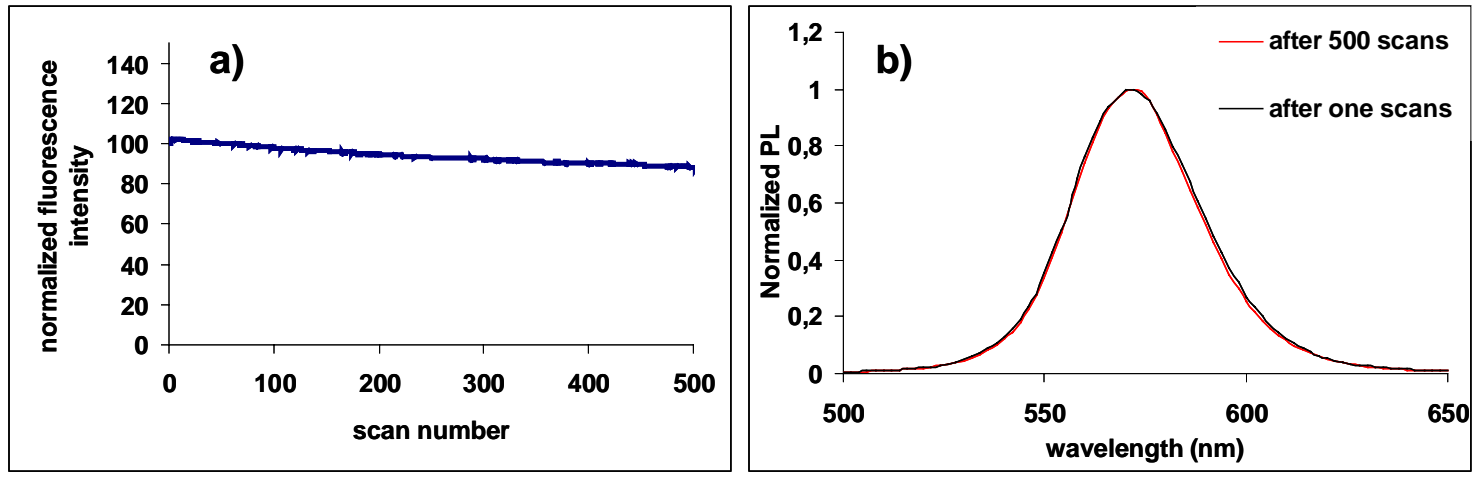

Figure 3 : (a) Photoluminescence intensity in function of number of excitation (excitation at $350 \mathrm{~nm}$, emission at $570 \mathrm{~nm}$ normalized to the initial value). (b) Comparison of the fluorescence spectra after one excitation and after 500 successive excitations at $350 \mathrm{~nm}$. 
Stability of QD-2a in saline solution was evaluated. The photoluminescence of water soluble QD2a in the presence of variable concentrations of $\mathrm{NaCl}$ was measured. From 0 to $1 \mathrm{M}[\mathrm{NaCl}]$, we observed no change in the fluorescence intensity and characteristics.
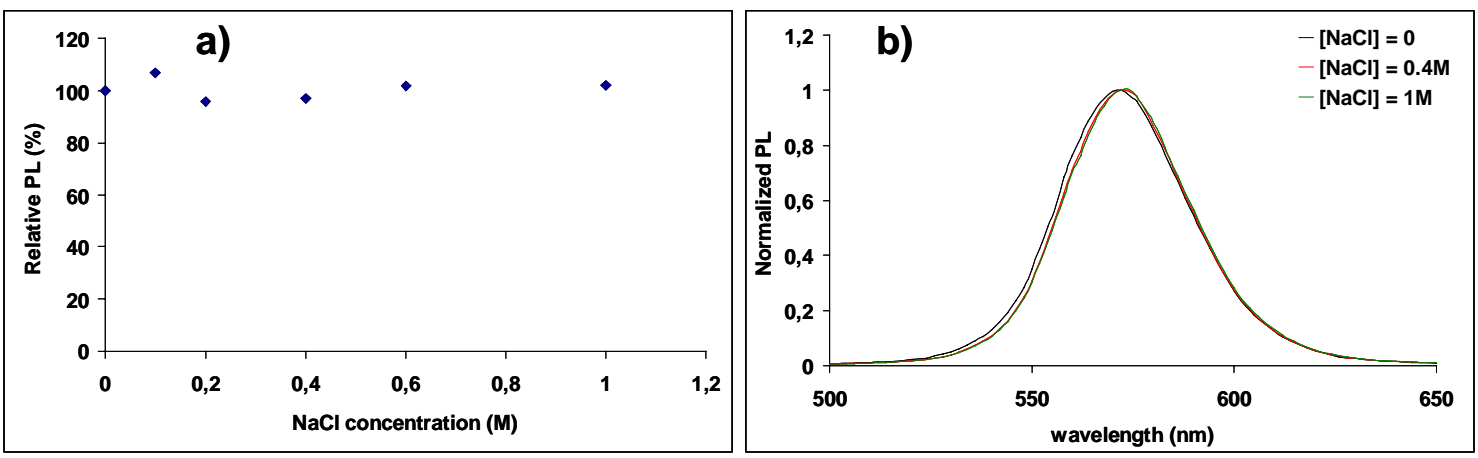

Figure $4:$ (a) Influence of the concentration of $\mathrm{NaCl}$ on the fluorescence intensity of QD-2a (excitation at 350 $\mathrm{nm}$, normalized fluorescence at $570 \mathrm{~nm}$ ). (b) Comparison of fluorescence spectra in presence of variable concentration of $\mathrm{NaCl}$ (excitations at $350 \mathrm{~nm}$ ). 